\title{
Testing the optimal defence hypothesis for two indirect defences: extrafloral nectar and volatile organic compounds
}

\author{
Venkatesan Radhika • Christian Kost • Stefan Bartram • \\ Martin Heil · Wilhelm Boland
}

Received: 16 December 2007 / Accepted: 2 May 2008 / Published online: 21 May 2008

(C) The Author(s) 2008

\begin{abstract}
Many plants respond to herbivory with an increased production of extrafloral nectar (EFN) and/or volatile organic compounds (VOCs) to attract predatory arthropods as an indirect defensive strategy. In this study, we tested whether these two indirect defences fit the optimal defence hypothesis (ODH), which predicts the withinplant allocation of anti-herbivore defences according to trade-offs between growth and defence. Using jasmonic acid-induced plants of Phaseolus lunatus and Ricinus communis, we tested whether the within-plant distribution pattern of these two indirect defences reflects the fitness value of the respective plant parts. Furthermore, we quantified photosynthetic rates and followed the within-plant transport of assimilates with ${ }^{13} \mathrm{C}$ labelling experiments. EFN secretion and VOC emission were highest in younger leaves. Moreover, the photosynthetic rate increased with leaf age, and pulse-labelling experiments suggested transport of carbon to younger leaves. Our results demonstrate that the ODH can explain the within-plant allocation pattern of both indirect defences studied.
\end{abstract}

V. Radhika $\cdot$ S. Bartram · W. Boland $(\bowtie)$

Department of Bioorganic Chemistry,

Max Planck Institute for Chemical Ecology,

Hans-Knöll-Str. 8, 07745 Jena, Germany

e-mail: boland@ice.mpg.de

C. Kost

Evolutionary Genetics and Microbial Ecology Laboratory,

New Zealand Institute for Advanced Study,

Massey University, Private Bag 102 904,

North Shore Mail Centre, Auckland, New Zealand

M. Heil

Dept. de Ing. Genética, CINVESTAV,

Irapuato. Km. 9.6 Libramiento Norte, Carretera Irapuato-León,

Apartado Postal 629, 36821 Irapuato, Guanajuato, México
Keywords Extrafloral nectar · Indirect defence · Ontogeny · Optimal defence hypothesis .

Volatile organic compounds
Abbreviations
DMNT (E)-4,8-dimethylnona-3,5,7-triene
EFN Extrafloral nectar
IAEA International Atomic Energy Agency
IRMS Isotope ratio mass spectrometry
LSD Least significant difference
JA Jasmonic acid
MeSA Methyl salicylate
ODH Optimal defence hypothesis
PAR Photosynthetic active radiation
PET Polyethyleneterephthalate
TMTT (E,E)-4,8,12-trimethyltrideca-1,3,7,11-tetraene
VBDB Vienna Peedee belemnite
VOC Volatile organic compounds

\section{Introduction}

Herbivores exert an immense selection pressure on plants, and the resulting arms-race has led to the evolution of an enormous variety of plant defences against herbivores (Walling 2000; Kessler and Baldwin 2002). Defences, which directly target the performance or survival of the herbivore, are generally referred to as 'direct' defences. In contrast, plant traits that do not directly affect the herbivore but rather function via the attraction, nourishment or housing of predatory organisms, thereby increasing the predation pressure on herbivores, are termed 'indirect' defences (Heil 2008). These plant defences, albeit often significantly contributing to the plant's ecological success, do however, not come without fitness costs (Gulmon and Mooney 1986). 
From an evolutionary perspective, any organism should respond to the resulting trade-offs in a way that maximises its reproductive output and minimises any investment in non-reproductive traits-even if they are essential for its survival. One example for such an evolutionary optimisation response that is generally regarded as a cost-saving strategy are herbivore-induced plant defences, which are activated only in case of an herbivore attack (Karban and Baldwin 1997; Dicke and Hilker 2003). The drawback of inducible defences, however, is the lag-time, which is the time required for the induction of the defence after the first contact with the herbivore, during which the plant remains vulnerable (Heil and Baldwin 2002; Zangerl 2003). Since most plant defences are neither consistently expressed throughout a plant's life nor evenly distributed within a plant (Zangerl and Rutledge 1996), several hypotheses have been suggested to predict their phenotypic variation depending on environmental or genetic factors (Karban and Baldwin 1997; Herms and Mattson 1992; Stamp 2003).

The optimal defence hypothesis (ODH) states that organisms evolved to allocate their defences in a way that maximises fitness (McKey 1974, 1979; Rhoades 1979). The underlying assumption is that defence is costly and thus, the spatio-temporal patterns of an adaptive defence allocation among plant parts should reflect the fitness-value of these organs (McKey 1974, 1979). In other words, the theoretical expectations of the ODH are that within a plant, young, still developing leaves should be better defended than older leaves.

However, physiological constraints may operate on plants, thereby causing them to deviate from these theoretical predictions. Empirical tests of the ODH are therefore required and many validating reports of this theory are indeed known for direct defences (Zangerl and Rutledge 1996; Ohnmeiss and Baldwin 2000; Barto and Cipollini 2005). Very little information, however, is available on the allocation pattern of indirect defensive strategies of plants.

This study aims at testing the predictions made by the ODH for two particularly widespread indirect defence traits: extrafloral nectar (EFN) and volatile organic compounds (VOCs), which are both involved in mediating the interaction between herbivore-damaged plants and members of the third trophic level (Arimura et al. 2005; Heil 2008). By offering EFN as a carbohydrate-rich reward (Bentley 1977; Koptur 1992) or by emitting VOCs that indicate the increased presence of potential prey to predators and parasitoids (Turlings et al. 1990; Pare and Tumlinson 1997), plants defend themselves indirectly against herbivores. Both EFN and VOCs are inducible traits, i.e. their production rate increases in response to herbivory or mechanical damage and this response is known to be regulated by the octadecanoid pathway, in which the phytohormone jasmonic acid (JA) plays a key role (Hopke et al.
1994; Heil et al. 2001). Exogenous treatment of plants with JA results in increased production rates of both EFN and VOCs, which closely resemble the plant's response induced by herbivore feeding in terms of quality and quantity (Dicke et al. 1999; Heil 2004).

We used lima bean (Phaseolus lunatus L., Fabacecae) and castor (Ricinus communis L., Euphorbiaceae) as experimental systems. Both plants bear extrafloral nectaries at the petioles of their leaves. In addition, lima bean releases VOCs after herbivory or when treated with JA that attract, e.g. carnivorous mites or parasitoid wasps under laboratory conditions (Dicke et al. 1999). At its natural growing site, JA-mediated EFN secretion has been shown to benefit the plant (Heil 2004; Kost and Heil 2005, 2008). In R. communis, herbivore or mechanical damage is known to increase EFN production (Wäckers et al. 2001). In the present investigation, we used JA to induce the production of EFN (both species) and VOCs (lima bean only) and tested the following predictions, which are derived from the ODH:

1. Both constitutive (i.e. untreated) and induced levels of EFN secretion and VOC emission are higher in younger leaves.

2. The ontogenetic pattern of indirect defence production (both EFN and VOCs) cannot be explained solely by the photosynthetic rate of the respective leaves.

3. Allocation of these defences to younger leaves is mediated by transporting newly assimilated carbohydrates from older source to younger sink leaves.

\section{Materials and methods}

Plant material and growth conditions

Plants of P. lunatus L. (lima bean) were cultivated from seeds derived from a native population growing in the coastal area near Puerto Escondido in the state of Oaxaca, Mexico. The parental plants have been used previously in field experiments on indirect plant defences (Heil 2004; Kost and Heil 2005, 2008). Ricinus communis L. plants (castor oil plant) were grown from seeds (Weber Seeds, Römhild, Germany) harvested from greenhouse-grown plants. Growing conditions were $20-22^{\circ} \mathrm{C}, 30-55 \%$ humidity during a $16 \mathrm{~h}$ photoperiod. Experiments were performed with 4-week-old plants (i.e. 5-6 leaf stage for P. lunatus and 4 leaf stage for $R$. communis). To study the ontogenetic pattern, both plants were grown in Klasmann clay substrate (Klasmann-Deilmann, Geeste, Germany). All experiments were performed in the greenhouse.

Numbering of leaves was based on their age as assessed by their insertion order into the main shoot. In P. lunatus, leaf 1 was the youngest, still unfolding leaf, leaves 2 and 3 
were mostly unfolded, and leaves 4 and 5 were slightly to completely hardened leaves, respectively (Fig. 1a). The four leaves of $R$. communis were numbered accordingly (Fig. 1d).

\section{Measurement of EFN secretion rates}

To ensure that no nectar was present at the onset of the experiment, extrafloral nectaries were rinsed thoroughly with tap water and allowed to dry. EFN secretion was quantified one day after spraying either tap water (control treatment) or an aqueous solution of 1 mM JA (JA treatment) on all the leaves until runoff. Plants were treated twice at an interval of $30 \mathrm{~min}$ and after that leaves were allowed to dry for $1 \mathrm{~h}$ before plants were placed back into the greenhouse. The EFN produced after $24 \mathrm{~h}$ was quantified as the amount of secreted soluble solids (i.e. sugars and amino acids) using a temperature-compensated refractometer (ATAGO N-10E refractometer, Leo Kübler $\mathrm{GmbH}$, Karlsruhe,
Germany) as described by Heil et al. (2000, 2001). EFN was quantified as amount of soluble solids per dry weight of the secreting leaf material per $24 \mathrm{~h}$.

Measurement of photosynthetic rate

The photosynthetic rate was measured with a portable open-mode photosynthesis system LI-6400 (LI-COR, Lincoln, NE, USA) using the 6400-15 Arabidopsis chamber on leaves attached to the plant. Measurements were taken between 9:00 a.m. and 2:00 p.m. using $360 \mu 11^{-1} \mathrm{CO}_{2}$ in the reference stream under approximately $900 \mu \mathrm{M} \mathrm{m}^{-2} \mathrm{~s}^{-1}$ PAR.

\section{Collection and analysis of VOCs}

The VOC emission as a function of leaf age in lima bean plants was measured by bagging all leaves individually in PET hoses (Toppits ${ }^{\circledR}$ 'Bratschlauch', Melitta, Minden,
Fig. 1 a Numbering of differentially aged leaves, b ontogenetic variation of EFN secretion rate $(n=9)$, and c photosynthetic rate $(n=6)$, of untreated and jasmonic acid (JA)-induced Phaseolus lunatus plants. d Numbering of differentially aged leaves, e EFN secretion rate $(n=7)$, and f photosynthetic rate $(n=7)$ of untreated and JA-induced R. communis plants. EFN secretion rate is given in milligrams of soluble solids per $\mathrm{g}$ leaf dry weight per $24 \mathrm{~h}$. The net photosynthetic rate is given as rates of $\mathrm{CO}_{2}$ uptake in $\mu \mathrm{mol} \mathrm{m} \mathrm{m}^{-2} \mathrm{~s}^{-1}$. Due to the small size, the photosynthetic rate of the youngest leaf could not be measured in $P$. lunatus.

Different letters denote significant differences between groups (global LSD post hoc for all factor combinations between leaf position and treatment after univariate ANOVA, $P<0.05$ ). Data are presented as mean $\pm 95 \% \mathrm{CI}$ (a) Phaseolus lunatus
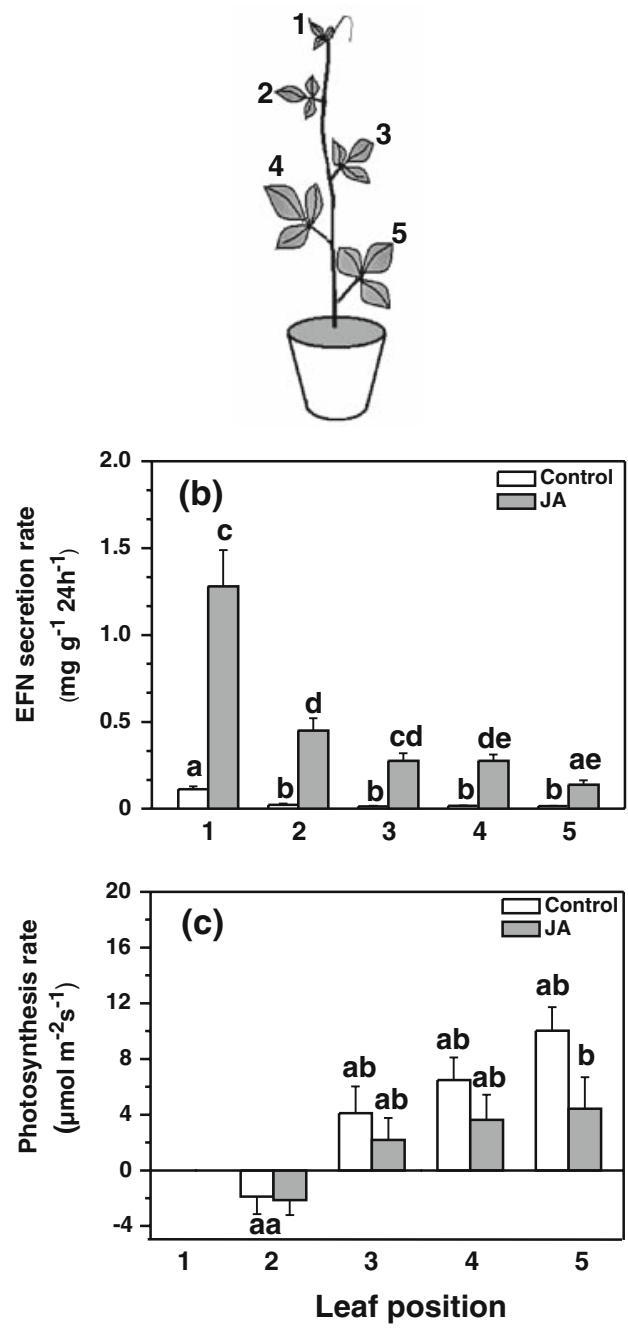

(d) Ricinus communis
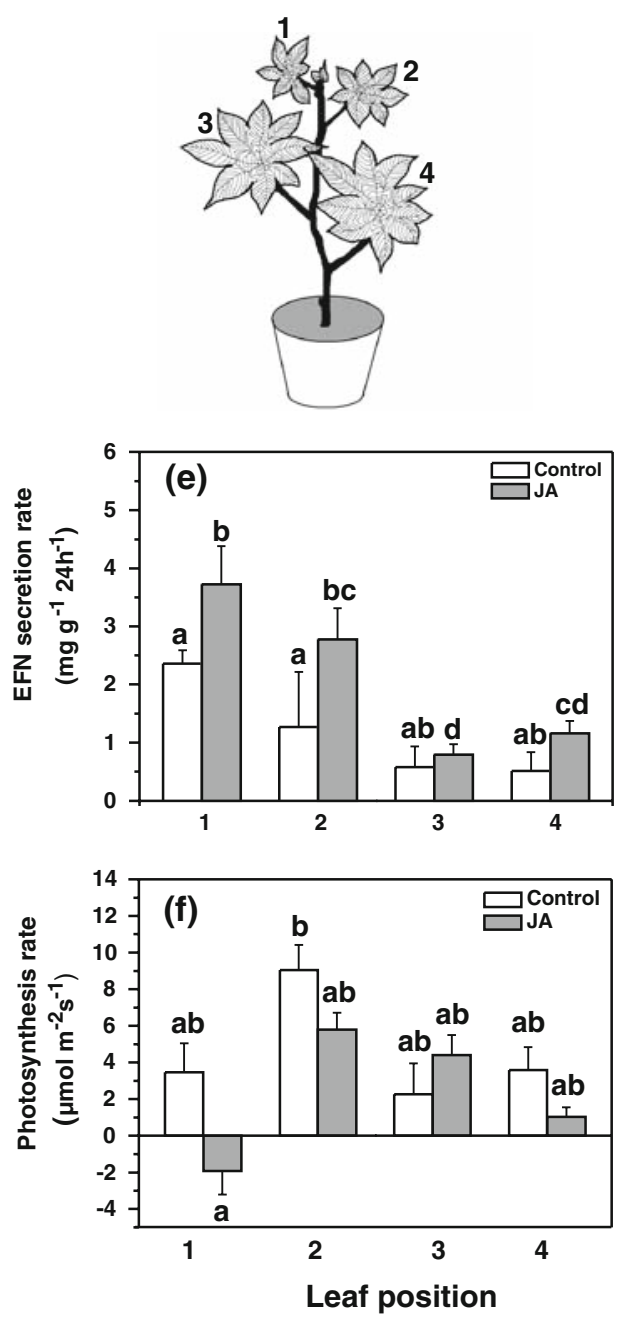
Germany) that do not emit detectable volatiles by themselves. VOCs emitted from each individual leaf were collected continuously for $24 \mathrm{~h}$ on charcoal traps $(1.5 \mathrm{mg}$ charcoal, Gränicher and Quartero, Daumazan sur Arize, France) by pulling air at about $500 \mathrm{ml} \mathrm{min}^{-1}$ using a $12 \mathrm{~V}$ vacuum pump (Gast Manufacturing, Benton Harbor, MI, USA). The traps were eluted with $2 \times 20 \mu \mathrm{l}$ of dichloromethane containing $200 \mathrm{ng}^{-1} \mathrm{l}^{-1}$ of 1 -bromodecane as an internal standard. The leaves were dried for dry weight determination. VOC samples were analysed on a Thermo Finnigan Trace GC-MS (Thermo, Bremen, Germany) equipped with a fused silica Alltech EC5 column $(15 \mathrm{~m} \times 0.25 \mathrm{~mm}$ internal diameter $\times 0.25 \mu \mathrm{m}$ film thickness) using $1.5 \mathrm{ml} \mathrm{min}^{-1}$ helium as carrier gas. Separation was achieved under programmed conditions $\left(45^{\circ} \mathrm{C}\right.$ for $2 \mathrm{~min}, 10^{\circ} \mathrm{C} \mathrm{min}{ }^{-1}$ to $200^{\circ} \mathrm{C}$, then $30^{\circ} \mathrm{C} \mathrm{min}^{-1}$ to $280^{\circ} \mathrm{C}$ for $1 \mathrm{~min}$; injector temperature: $220^{\circ} \mathrm{C}$ ). MS analysis was performed on a TraceMS in electron impact full-scan mode at $70 \mathrm{eV}$ with source temperature at $200^{\circ} \mathrm{C}$ and GC interface temperature at $280^{\circ} \mathrm{C}$. Individual compounds were quantified with respect to the peak area of the internal standard and related to the dry weight of the leaf. The ten most dominantly emitted compounds, namely ( $Z$ )-3-hexenyl-acetate, (E)- $\beta$-ocimene, $\quad(R)$-(-)-linalool, $(E)$-4,8-dimethylnona1,3,7-triene (DMNT), (E)-2,6-dimethyloctatetraene $\left(\mathrm{C}_{10} \mathrm{H}_{14}\right)$, methyl salicylate (MeSA), 2,6-dimethyl-3,5,7-octatriene-2-ol $\left(\mathrm{C}_{10} \mathrm{H}_{16} \mathrm{O}\right)$, cis-jasmone, $(E)$ - $\beta$-caryophyllene, and $(E, E)$ 4,8,12-trimethyltrideca-1,3,7,11-tetraene (TMTT), were summed up to test for a putative effect of leaf position on total VOC emission.

\section{Labelling experiment}

In order to follow the internal transport of newly assimilated carbon, experiments were performed using synthetically premixed air containing ${ }^{13} \mathrm{CO}_{2}$ instead of ${ }^{12} \mathrm{CO}_{2}$ at a natural concentration of $380 \mathrm{ppm}$. In all cases, the air with ${ }^{13} \mathrm{CO}_{2}$ was purged for $24 \mathrm{~h}$ after induction with $1 \mathrm{mM} \mathrm{JA}$ solution. For each plant, each of five leaves were bagged individually in a PET hose (i.e. 'Bratschlauch', see above) and in each case, one of the five leaves was purged with labelled air, while all the other four leaves were purged with normal air. After $24 \mathrm{~h}$, the ${ }^{13} \mathrm{C}$ content in the tissue of all five leaves as well as in the EFN secreted from this leaf was quantified using an isotope ratio mass spectrometer (IRMS). This procedure was applied to a total of eight replicates of four plants each, with one of the five leaves having experienced the ${ }^{13} \mathrm{CO}_{2}$-treatment until each leaf position within the four-plant group had received the ${ }^{13} \mathrm{C}$ treatment once. Due to technical reasons, we focussed this analysis on leaves in positions $1-3$ and 5 .

For IRMS measurements of EFN, nectar samples were filled in small $0.04 \mathrm{ml}$ tin capsules for liquid samples (d:
$3.5 \mathrm{~mm}$, 1: $5.5 \mathrm{~mm}$; part. No. 184.9915.26, Lüdi AG, Flawil, Switzerland), dried in a desiccator filled with $\mathrm{P}_{2} \mathrm{O}_{5}$ as drying agent, and weighed before further analysis. For the solid leaf sample measurements, dried and powdered leaf material was weighed in $0.07 \mathrm{ml}$ tin capsules $(\mathrm{d}: 4.0 \mathrm{~mm}, \mathrm{l}$ : $6.0 \mathrm{~mm}$; part. No. 176.1305.53, Lüdi AG). Capsules were sealed and combusted (oxidation at $1,020^{\circ} \mathrm{C}$, reduction at $\left.650^{\circ} \mathrm{C}\right)$ in a constant helium stream $\left(80 \mathrm{ml} \mathrm{min}^{-1}\right)$ quantitatively to $\mathrm{CO}_{2}, \mathrm{~N}_{2}$, and $\mathrm{H}_{2} \mathrm{O}$ using an elemental analyzer (EuroEA CN2 dual, HEKAtech, Wegberg, Germany). After passing a water trap $\left(\mathrm{MgClO}_{4}\right)$, the gases were separated chromatographically at $85^{\circ} \mathrm{C}$ and transferred via an open split to a coupled isotope ratio mass spectrometer (IsoPrime, Micromass, Manchester, UK). Our laboratory working standard (acetanilide) has been calibrated on the VPDB scale using IAEA reference material, NBS 22, with a $\delta{ }^{13} \mathrm{C}$ value of $-29.78 \%$ (Werner and Brand 2001). All isotope ratios are given as $\delta{ }^{13} \mathrm{C}$ values: $\delta{ }^{13} \mathrm{C}(\%)=$ $\left[\left(R_{\text {sample }} / R_{\text {standard }}\right)-1\right] \times 10^{3}$, where $R$ corresponds to the ${ }^{13} \mathrm{C} /{ }^{12} \mathrm{C}$ ratio of the sample and the standard.

\section{Statistical analysis}

All experiments were analysed with linear mixed-effect models with 'treatment' as fixed and 'plant individual' as random factor. Values of EFN secretion and total VOC emission have been log-transformed to meet the test assumptions of normality and homogeneity of variances. Global LSD post hoc tests were applied to the measured values for EFN secretion, VOC emission, and photosynthetic rates to test for between-group differences between all factor combinations of leaf position and treatment. All statistical analyses were performed using SPSS 13.0 (SPSS Inc., Chicago, IL, USA). To control for multiple testing in comparing qualitative differences in the VOCs blend with leaf age, false-discovery rate (FDR) procedure was used.

\section{Results}

Ontogenetic pattern of EFN production

In both, $P$. lunatus and $R$. communis, the youngest leaf (i.e. leaf position 1) secreted the highest amount of EFN in undamaged controls as well as in JA-treated plants and the EFN secretion rate significantly decreased with leaf age (Fig. 1b, e, LSD post hoc test after univariate ANOVA: $P<0.01, n=9$ and 7 , respectively). In case of lima bean, the mean amount of EFN secreted from the youngest leaf exceeded that of the oldest leaf about fivefold. In this species, the two youngest leaves secreted on average two times more EFN than the two older leaves. An analysis of the inducibility with respect to leaf age indicated that in both 
plant species the youngest leaf did not only show the highest level of constitutive EFN secretion, but was also inducible to higher defence levels than the older leaves (LSD post hoc test after univariate ANOVA, $P<0.05, n=9$ in lima bean and $n=7$ in $R$. communis).

\section{Ontogenetic pattern of photosynthetic rate}

Quantification of the photosynthetic rate indicated that younger leaves showed a lower gas exchange capacity than older ones in both control and JA-treated plants (Fig. 1c, f, LSD post-hoc test after univariate ANOVA: $P<0.02, n=6$ and 7 , respectively), thus indicating a negative relation between EFN production and photosynthetic capacity. JA treatment did not significantly alter the photosynthetic rate in both plant species investigated (univariate ANOVA, $P>0.05, n=7$ in lima bean and $n=6$ in $R$. communis).

\section{Labelling experiment}

Due to the absence of a positive relation between photosynthetic rate and EFN secretion (Fig. 1), we hypothesized that there should be a flow of photosynthates within the plant from older source to younger sink leaves. In labelling experiments with lima bean plants, in which one of five leaves was purged with artificial air containing ${ }^{13} \mathrm{CO}_{2}$ at $380 \mathrm{ppm}$ while the other leaves were treated with natural air for $24 \mathrm{~h}$, we measured the ${ }^{13} \mathrm{C} /{ }^{12} \mathrm{C}$-ratios of the $\mathrm{EFN}$ from each leaf (Fig. 2a) and the corresponding leaf tissue (Fig. 2b). After labelling leaf 1 , no increased ${ }^{13} \mathrm{C}$ concentration in the tissues as well as EFN of the untreated leaves was observed. Treatment of leaves 2 and 3 showed for some replicates a clear, but for others only a slightly increased incorporation of ${ }^{13} \mathrm{C}$ into the younger leaves 1 or 1 and 2 , respectively. In no case was a downstream transport, i.e., from the younger (1-3) to older (4-5) leaves, observed. The $\delta^{13} \mathrm{C}$ values of downstream leaves were in all experiments close to the natural abundance level $(-20$ to $-30 \%$; i.e. values of control plants). Labelling of leaf 5 led to a strong incorporation of ${ }^{13} \mathrm{C}$ in the tissues and the $\mathrm{EFN}$ of leaves 3, 2 and 1 . The incorporation of ${ }^{13} \mathrm{C}$ in the leaf material was strongest in the most distal leaf number 1 and decreased continuously with increasing leaf age (i.e. the level of incorporation followed the leaf order $5^{*} \gg 1>2>3>4, *=$ labelled leaf).

No increase of ${ }^{13} \mathrm{C}$ in the tissue and the EFN of leaf 4 could be detected, not even after treatment of leaf 5 . In all experiments, the $\delta^{13} \mathrm{C}$ values of leaf 4 were in the range of the natural abundance level. The amount of ${ }^{13} \mathrm{C}$ incorporated into EFN was on average about ninefold higher than that observed for the leaf tissue. Taken together, this experiment revealed a unidirectional transport of photosynthates from older source to younger sink leafs. Furthermore, no photosynthetic products were transported to leaf 4 and no transport occurred downstream to older leaves.

\section{Ontogenetic pattern of VOC emission}

Volatile organic compounds emitted from individual leaves were collected from uninduced controls and JA-treated lima bean plants and compared among leaf positions (Fig. 3). The total amount of VOCs released after induction from young leaves was significantly higher than the amounts emitted from older leaves (LSD post hoc test after univariate ANOVA, $P<0.01, n=8$ ). Constitutive VOC emission levels, however, were extremely low in leaf number 1 and virtually absent in all other leaves (Fig. 3). JA induction significantly increased the total VOC emission of leaves 1 and 2 over that of the older leaves 3, 4, and 5 (univariate ANOVA, $P<0.01, n=8$ ). Similar to our observation for the EFN secretion, the youngest lima bean leaf showed both the highest level of constitutive VOC emission and was inducible to higher levels than all the older leaves. Qualitative changes among differently aged leaves were observed in some of the main constituents of the emitted VOC blend (Fig. 3b, FDR-corrected univariate ANOVA: $P \leq 0.03, n=8)$. No significant difference was observed in levels of (Z)-cis-3-hexenyl acetate, MeSA, $\beta$-caryophyllene and TMTT emitted with leaf positions. In general, younger leaves (leaf positions 1-3) emitted more volatiles than the older leaves (leaf positions 4-5).

\section{Discussion}

The ODH predicts that the spatial allocation of defensive traits within a plant should favour more valuable and vulnerable plant parts (McKey 1974, 1979; Rhoades 1979). In line with these predictions, the young leaves of both lima bean and castor showed the highest level of the two indirect defences, EFN secretion and VOC emission (Figs. 1b, e, 3). Young leaves are generally important for future plant fitness since they already have caused high construction costs without having contributed very much yet to the plant's pool of photo-assimilates. Consequently, they have the highest future life span and can therefore be expected to contribute bulk to the prospective photosynthetic assimilation. Moreover, very young leaves usually still lack effective mechanical defences (Harper 1989) and indeed it has been shown for several plant species that young leaves, which are more nutritious (Slansky 1993), suffer more from herbivory than older ones within the same plant (Kursar and Coley 1991; Boege and Marquis 2006). Our results show that the young leaves are defended more, both before and after induction (Fig. 1). This observation is in line with the interpretation that EFN and VOCs are allocated based 
Fig. 2 Accumulation of ${ }^{13} \mathrm{C}$ in $\mathbf{a}$ EFN of lima bean plants when leaf position $1(n=8), 2,3$ $(n=7)$, and $5(n=6)$ were purged with air containing ${ }^{13} \mathrm{CO}_{2}(\mathbf{a})$, and leaf tissue $(n=6)$ when leaf positions 1,2, 3 and 5 were purged with air containing ${ }^{13} \mathrm{CO}_{2}(\mathbf{b})$. Values are given as $\delta^{13} \mathrm{C}(\% o)$ with different symbols representing individual replicates. The grey box denotes the leaf position purged with air containing ${ }^{13} \mathrm{CO}_{2}$. The dashed line indicates the trend of the mean values of all replicates. Different letters indicate significant differences among leaf positions (LSD post hoc after univariate ANOVA, $P<0.05$ ) (a)

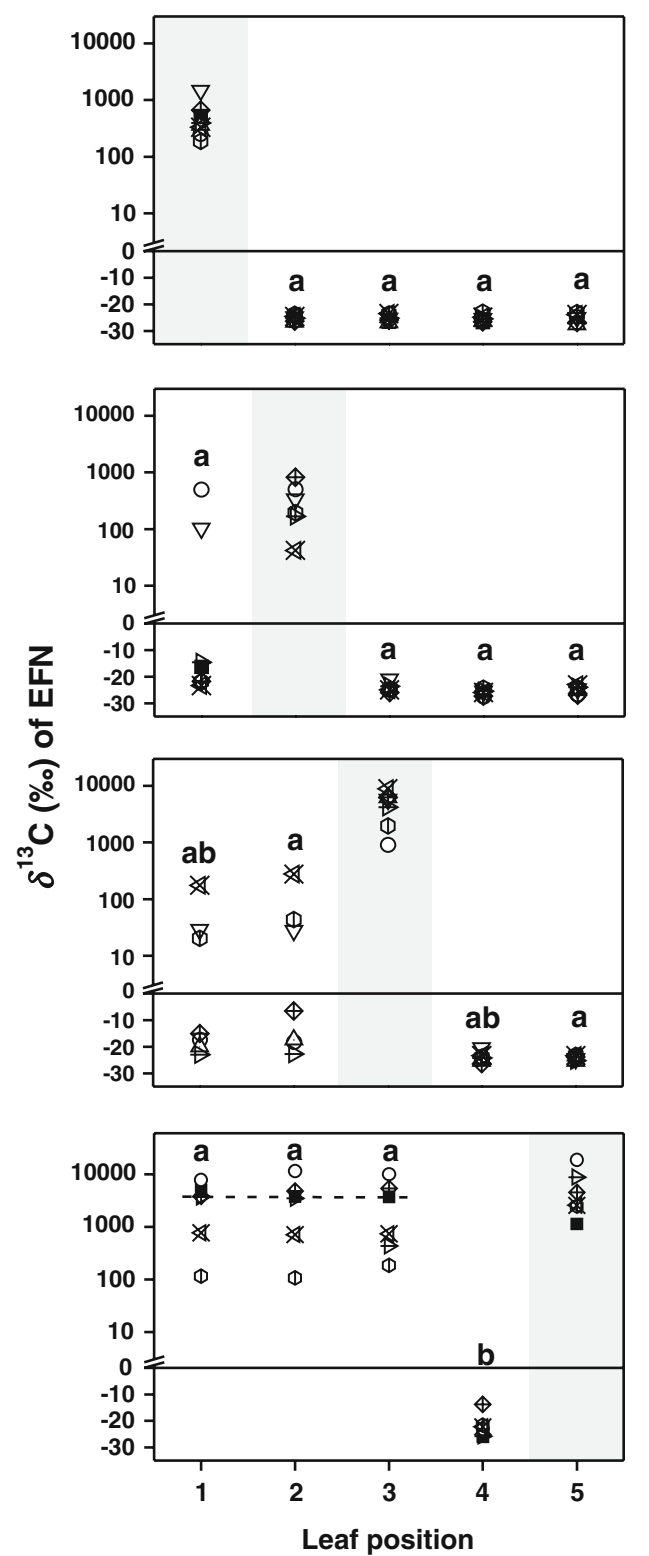

(b)
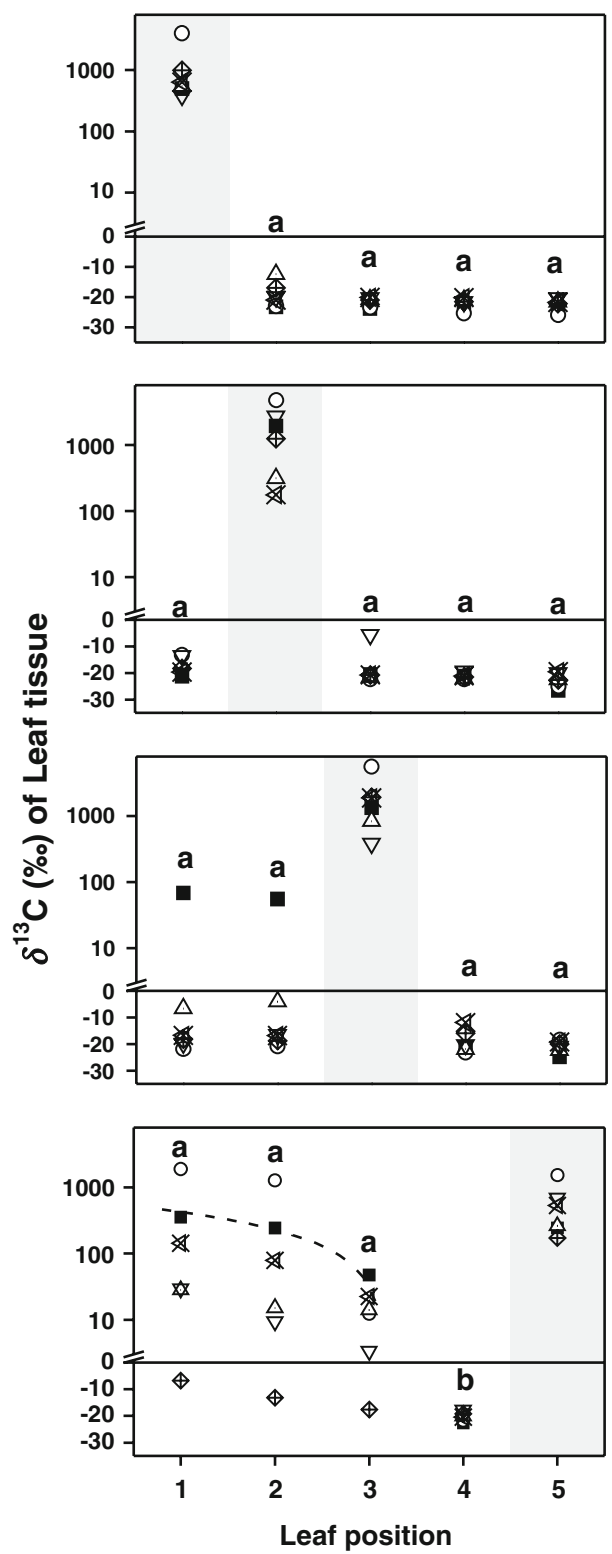

on the value and probability of attack of the leaves, as predicted by the ODH (Anderson and Agrell 2005). Also in the lima bean, which is a cyanogenic plant species, similar patterns have already been demonstrated for its direct defence, as young leaves were characterised by increased amounts of cyanide-containing precursors and higher capacities to release HCN per time unit than mature leaves (Ballhorn et al. 2005).

Our study lends support to previous findings where more valuable plant parts showed increased defence levels upon herbivore feeding (Heil et al. 2000; Wäckers and Bonifay 2004; Rostas and Eggert 2008). Furthermore, it is known that in myrmecophytes, ants preferably patrol and defend young leaves (Heil et al. 2001). In obligate ant-plants, however, this pattern is not necessarily caused by the spatial distribution of ant rewards (i.e. food bodies and EFN; Heil et al. 1997), but could also be achieved by special behavioural adaptations of the ants (Heil et al. 2004). In contrast, optimal distributions of defenders in facultative interactions with unspecialised animals require that the plants distribute the attractive traits accordingly (Downhower 1975; Heil et al. 2000).

Indeed, the overall emission rate of VOCs increased from young to older leaves, while the qualitative composition of the emitted blend changed only slightly. Both the quantitative and qualitative emission of VOCs have been shown to be highly variable depending on several interacting factors such as plant and herbivore species, type of damage (chewing vs. piercing-sucking) and abiotic factors 
Fig. 3 a Ontogenetic variation of the total VOC emission (mean $\pm 95 \%$ CI) of lima bean plants $(n=8)$. The amount of emitted VOCs is given as peak area $\left(A_{\mathrm{voc}}\right)$ relative to the peak area of an internal standard $\left(A_{\mathrm{IS}}\right)$ per $24 \mathrm{~h}$ per g leaf dry weight. Different letters denote significant differences between groups (global LSD post hoc for all factor combinations between leaf position and treatment after univariate ANOVA, $P<0.05)$. b Mean $( \pm 95 \% \mathrm{CI})$ relative amounts of volatiles emitted by JA-treated plants as determined by the ratio of peak area of the particular compound $\left(A_{\mathrm{VOC}}\right)$ to the peak area of the internal standard $\left(A_{\mathrm{IS}}\right)$ per $24 \mathrm{~h}$ per $\mathrm{g}$ dry weight. Different letters denote significant differences among leaf positions as determined with a FDR-corrected univariate ANOVA: $P \leq 0.03, n=8$. $T r$ trace quantities (i.e. $\leq 0.005$ ). Ten most dominant peaks of the TIC were chosen: 1 (3Z)-hexenyl acetate, 2 ocimene, $3(R)$-linalool, 4 DMNT, $5 \mathrm{C}_{10} \mathrm{H}_{14}, 6$ methyl salicylate, $7 \mathrm{C}_{10} \mathrm{H}_{16} \mathrm{O}, 8$ cis-jasmone, $9 \beta$-caryophyllene, 10 TMTT
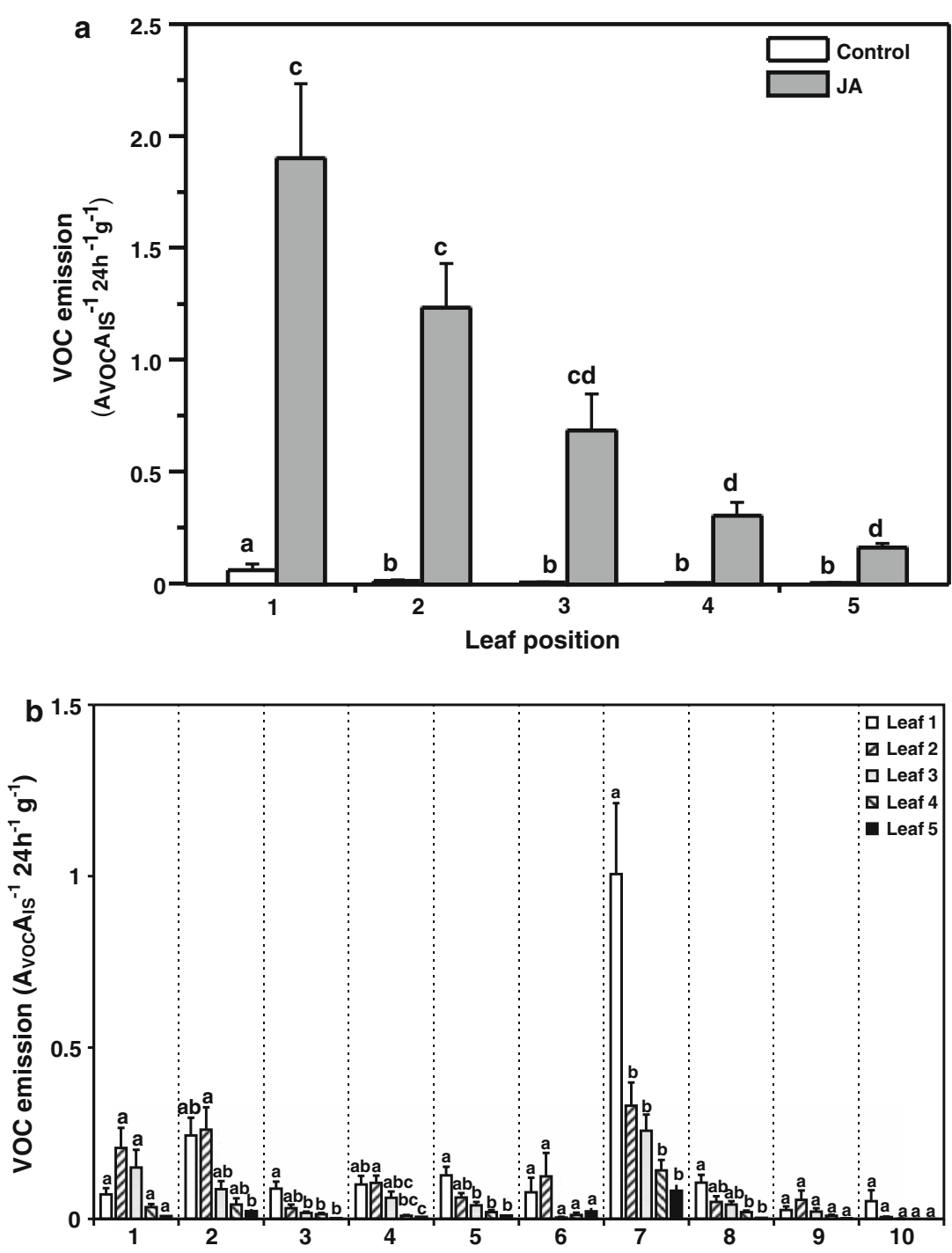

like rainfall and light intensity (for review, see Arimura et al. 2005). Our finding that VOCs are emitted more from younger leaves could be interpreted as a strategy of a directional attraction of parasitoids or other arthropod predators to younger leaves (Hazarika et al. 2007) — a hypothesis that remains to be tested in future studies.

The consistent release patterns of EFN and VOCs give rise to the question whether both traits contribute equally to the plant's protection. Since it was recently shown for lima bean that VOCs act as airborne signals and induce EFN secretion in undamaged plant parts (Kost and Heil 2006; Heil and Silva Bueno 2007), an alternative scenario to the defense hypothesis could be that the primary function of the emitted VOCs is to induce EFN. In this case, parasitoids and other insect predators learning to associate increased VOC levels with an increased presence of herbivores could be a secondary function of the emitted VOCs.

Furthermore, the cost of these two indirect defences remains elusive, though VOCs have been estimated to cause low costs in corn plants (Hoballah et al. 2004). VOCs and EFN are carbon-based defences and thus might even compete for a common pool of metabolites. The amount of VOCs emitted ranges orders of magnitudes below the amount of carbohydrates that is secreted as EFN. In case of the lima bean for example, a young leaf emits only $1.9 \mathrm{ng} /$ $24 \mathrm{~h} \mathrm{~g}^{-1}$ dry weight of mainly carbon-based VOCs, while the same leaf secretes $1.3 \mathrm{mg} E F N / 24 \mathrm{~h} \mathrm{~g}^{-1}$ dry weight as sugars. It is thus likely that EFN accounts for higher metabolic costs than VOCs. However, further investigation is needed to fully understand the partitioning of plant metabolites for these two indirect defences and future studies must be directed to assess these costs and benefits of both VOC emission and EFN secretion under different herbivore pressures and inductive situations.

Despite being shaped by evolution as an adaptive response, the spatio-temporal distribution of defence traits within plants has to obey limitations in organ-wide or plantwide resource availabilities. EFN and VOCs are primarily 
carbon-based defences, and differences in photosynthetic $\mathrm{C}$-assimilation among organs may thus also cause different production rates of these defensive traits. However, patterns in $\mathrm{C}$-assimilation did not entirely match those observed for EFN and VOCs production, as older leaves were generally characterised by higher photosynthetic rates than younger leaves. On average, younger leaves showed a negative photosynthesis (Fig. 1c, f), i.e. respiration rate was higher than the rate of $\mathrm{C}$-assimilation.

Leaf photosynthesis is the main source for the sugars secreted as EFN (Wardlaw 1990). Young, still developing leaves were characterised by low photosynthetic rates (Fig. 1c, f) and presumably had very low reserves for producing defensive compounds (Larson and Gordon 1969). Thus, they act as physiological sinks and import nutrients until they become competent enough to synthesize defence compounds on their own (Lalonde et al. 2004). Indeed, our ${ }^{13} \mathrm{C}$ labelling experiment in lima bean plants indicated a net transport of $\mathrm{C}$ assimilated by leaf 5 to younger leaves (1-3; Fig. 2) when all leaves were treated with JA. This result illustrates the transport of photosynthates within the plant from mature to young leaves, where protection is most essential. This finding is in line with previous studies showing that plants can metabolically reorganize in response to herbivory by reallocating resources to growing plant parts (Strauss and Agrawal 1999; Hui et al. 2003) as well as by making younger leaves stronger sinks for defensive metabolites (Arnold and Schultz 2002).

Transport of photosynthates depends on the vascular architecture, and studies have shown that the systemic induction of plant defences can depend on the way the leaves are connected by the vascular system (Davis et al. 1991; Orians et al. 2000; Schittko and Baldwin 2003; Orians 2005; Gomez and Stuefer 2006). In our study, we mimicked herbivory on a plant-wide level by spraying JA on all leaves. In this inductive situation, all the observed pattern could be explained with the ODH.

In summary, we have tested the predictions made by the ODH for two of the most widely distributed indirect plant defences, secretion of EFN and emission of VOCs. We have shown that the plant's induced defensive strategy involves channelling resources in a way that maximises the protection of its most valuable parts. This result is consistent with the $\mathrm{ODH}$ in that the youngest leaf, which is a greater contributor towards future plant fitness, enjoys higher defence levels by importing carbohydrates from older leaves. To our knowledge, this is the first report verifying that the within-plant distribution pattern of these two indirect defences does not simply reflect patterns of carbon assimilation, but actually represents an optimal defence strategy.

Acknowledgments The authors thank Dr. Willi A. Brand and Heike Geilmann for support with standards for the IRMS measurements as well as Henry Busch, Jens Burkhardt, and Anja David who helped with preliminary experiments. Financial support by the International MaxPlanck Research School (IMPRS) and the Max-Planck Society (MPG) is gratefully acknowledged.

Open Access This article is distributed under the terms of the Creative Commons Attribution Noncommercial License which permits any noncommercial use, distribution, and reproduction in any medium, provided the original author(s) and source are credited.

\section{References}

Anderson P, Agrell J (2005) Within-plant variation in induced defence in developing leaves of cotton plants. Oecologia 144:427-434

Arimura G, Kost C, Boland W (2005) Herbivore-induced, indirect plant defences. Biochim Biophys Acta Mol Cell Biol Lipids 1734:91-111

Arnold TM, Schultz JC (2002) Induced sink strength as a prerequisite for induced tannin biosynthesis in developing leaves of Populus. Oecologia 130:585-593

Ballhorn DJ, Lieberei R, Ganzhorn JU (2005) Plant cyanogenesis of Phaseolus lunatus and its relevance for herbivore-plant interaction: the importance of quantitative data. J Chem Ecol 31:14451473

Barto EK, Cipollini D (2005) Testing the optimal defence theory and the growth-differentiation balance hypothesis in Arabidopsis thaliana. Oecologia 146:169-178

Bentley BL (1977) Extra-floral nectaries and protection by pugnacious bodyguards. Annu Rev Ecol Syst 8:407-427

Boege K, Marquis RJ (2006) Plant quality and predation risk mediated by plant ontogeny: consequences for herbivores and plants. Oikos 115:559-572

Davis JM, Gordon MP, Smit BA (1991) Assimilate movement dictates remote sites of wound-induced gene-expression in poplar leaves. Proc Natl Acad Sci USA 88:2393-2396

Dicke M, Hilker M (2003) Induced plant defences: From molecular biology to evolutionary ecology. Basic Appl Ecol 4:3-14

Dicke M, Gols R, Ludeking D, Posthumus MA (1999) Jasmonic acid and herbivory differentially induce carnivore-attracting plant volatiles in Lima bean plants. J Chem Ecol 25:1907-1922

Downhower JF (1975) The distribution of ants on Cecropia leaves. Biotropica 7:59-62

Gomez S, Stuefer JF (2006) Members only: induced systemic resistance to herbivory in a clonal plant network. Oecologia 147:461468

Gulmon SL, Mooney HA (1986) Costs of defence and their effects on plant productivity. In: Givnish TJ (ed) On the economy of plant form and function. University press, Cambridge, pp 691-698

Harper JL (1989) The value of a leaf. Oecologia 80:53-58

Hazarika LK, Deka M, Bhuyan M (2007) Oviposition behaviour of the rice hispa Dicladispa armigera (Coleoptera: Chrysomelidae). Intl J Trop Insect Sci 25:50-54

Heil M (2004) Induction of two indirect defences benefits Lima bean (Phaseolus lunatus, Fabaceae) in nature. J Ecol 92:527-536

Heil M (2008) Indirect defence via tritrophic interactions. New Phytol 178:41-61

Heil M, Baldwin IT (2002) Fitness costs of induced resistance: emerging experimental support for a slippery concept. Trends Plant Sci 7:61-67

Heil M, Silva Bueno JC (2007) Within-plant signaling by volatiles leads to induction and priming of an indirect plant defense in nature. Proc Nat Acad Sci USA 104:5467-5472

Heil M, Fiala B, Linsenmair KE, Zotz G, Menke P, Maschwitz U (1997) Food body production in Macaranga triloba (Euphorbiaceae): a 
plant investment in anti-herbivore defence via symbiotic ant partners. J Ecol 85:847-861

Heil M, Fiala B, Baumann B, Linsenmair KE (2000) Temporal, spatial and biotic variations in extrafloral nectar secretion by Macaranga tanarius. Funct Ecol 14:749-757

Heil M, Koch T, Hilpert A, Fiala B, Boland W, Linsenmair KE (2001) Extrafloral nectar production of the ant-associated plant, Macaranga tanarius, is an induced, indirect, defensive response elicited by jasmonic acid. Proc Natl Acad Sci USA 98:10831088

Heil M, Feil D, Hilpert A, Linsenmair KE (2004) Spatiotemporal patterns in indirect defence of a south-east Asian ant-plant support the optimal defence hypothesis. J Trop Ecol 20:573-580

Herms DA, Mattson WJ (1992) The dilemma of plants: to grow or defend. Quart Rev Biol 67:283-335

Hoballah ME, Kollner TG, Degenhardt J, Turlings TCJ (2004) Costs of induced volatile production in maize. Oikos 105:168-180

Hopke J, Donath J, Blechert S, Boland W (1994) Herbivore-induced volatiles - the emission of acyclic homoterpenes from leaves of Phaseolus lunatus and Zea mays can be triggered by a beta-glucosidase and jasmonic acid. FEBS Lett 352:146-150

Hui DQ, Iqbal J, Lehmann K, Gase K, Saluz HP, Baldwin IT (2003) Molecular interactions between the specialist herbivore Manduca sexta (Lepidoptera, Sphingidae) and its natural host Nicotiana attenuata: V. Microarray analysis and further characterization of large-scale changes in herbivore-induced mRNAs. Plant Physiol 131:1877-1893

Karban R, Baldwin IT (1997) Induced responses to herbivory. The University of Chicago Press, Chicago

Kessler A, Baldwin IT (2002) Plant responses to insect herbivory: the emerging molecular analysis. Annu Rev Plant Biol 53:299-328

Koptur S (1992) Extrafloral nectary mediated interactions between insects and plants. In: Bernays E (ed) Insect-plant interactions. CRC press, Boca Raton, pp 81-129

Kost C, Heil M (2005) Increased availability of extrafloral nectar reduces herbivory in Lima bean plants (Phaseolus lunatus, Fabaceae). Basic Appl Ecol 6:237-248

Kost C, Heil M (2006) Herbivore-induced plant volatiles induce an indirect defence in neighbouring plants. J Ecol 94:619-628

Kost C, Heil M (2008) Defensive role of volatile emission and extrafloral nectar secretion for Lima bean in nature. J Chem Ecol. doi:10.1007/s10886-007-9404-0

Kursar TA, Coley PD (1991) Nitrogen-content and expansion rate of young leaves of rain-forest species-implications for herbivory. Biotropica 23:141-150

Lalonde S, Wipf D, Frommer WB (2004) Transport mechanisms for organic forms of carbon and nitrogen between source and sink. Annu Rev Plant Biol 55:341-372

Larson PR, Gordon JC (1969) Leaf development, photosynthesis, and $\mathrm{C}^{14}$ distribution in Populus deltoides seedlings. Am J Bot 56:1058-1066

McKey D (1974) Adaptive patterns in alkaloid physiology. Am Nat 108:305-320
McKey D (1979) The distribution of plant secondary compounds within plants. In: Rosenthal GA, Janzen DH (eds) Herbivores: their interactions with secondary plant metabolites. Academic press, New York, pp 55-133

Ohnmeiss TE, Baldwin IT (2000) Optimal defence theory predicts the ontogeny of an induced nicotine defence. Ecology 81:1765-1783

Orians C (2005) Herbivores, vascular pathways and systemic induction: facts and artifacts. J Chem Ecol 31:2231-2242

Orians CM, Pomerleau J, Ricco R (2000) Vascular architecture generates fine scale variation in the systemic induction of proteinase inhibitors in tomato. J Chem Ecol 26:471-485

Pare PW, Tumlinson JH (1997) De novo biosynthesis of volatiles induced by insect herbivory in cotton plants. Plant Physiol 114:1161-1167

Rhoades DF (1979) Evolution of plant defense against herbivores. In: Rosenthal GA, Janzen DH (eds) Herbivores: their interaction with secondary metabolites. Academic Press, New York, pp 1-55

Rostas M, Eggert K (2008) Ontogenetic and spatio-temporal patterns of induced volatiles in Glycine max in the light of the optimal defence hypothesis. Chemoecology 18:29-38

Schittko U, Baldwin IT (2003) Constraints to herbivore-induced systemic responses: bidirectional signaling along orthostichies in Nicotiana attenuate. J Chem Ecol 29:763-770

Slansky F (1993) Nutritive ecology: the fundamental quest for nutrients. In: Stamp NE, Casey TM (eds) Caterpillars-ecological and evolutionary constraints on foraging. Chapman \& Hall, New York, pp 29-91

Stamp N (2003) Out of the quagmire of plant defense hypotheses. Q Rev Biol 78:23-55

Strauss SY, Agrawal AA (1999) The ecology and evolution of plant tolerance to herbivory. Trends Ecol Evol 14:179-185

Turlings TCJ, Tumlinson JH, Lewis WJ (1990) Exploitation of herbivore-induced plant odors by host-seeking parasitic wasps. Science 250:1251-1253

Wäckers FL, Bonifay C (2004) How to be sweet? Extrafloral nectar allocation by Gossypium hirsutum fits optimal defence theory predictions. Ecology 85:1512-1518

Wäckers FL, Zuber D, Wunderlin R, Keller F (2001) The effect of herbivory on temporal and spatial dynamics of foliar nectar production in cotton and castor. Ann Bot 87:365-370

Walling LL (2000) The myriad plant responses to herbivores. J Plant Growth Regul 19:195-216

Wardlaw IF (1990) Tansley review no 27-the control of carbon partitioning in plants. New Phytol 116:341-381

Werner RA, Brand WA (2001) Referencing strategies and techniques in stable isotope ratio analysis. Rapid Commun Mass Spectrom 15:501-519

Zangerl AR (2003) Evolution of induced plant responses to herbivores. Basic Appl Ecol 4:91-103

Zangerl AR, Rutledge CE (1996) The probability of attack and patterns of constitutive and induced defence: A test of optimal defence theory. Am Nat 147:599-608 